\title{
層の削除と再学習によるResNetのモデル圧縮
}

\section{Model Compression for ResNet via Layer Erasure and Re-training}

\author{
井田安俊 \\ 日本電信電話株式会社 NTT ソフトウェアイノベーションセンタ \\ NTT Software Innovation Center \\ yasutoshi.idalieee.org \\ 藤原 靖宏 \\ 日本電信電話株式会社 NTT コミュニケーション科学基礎研究所
NTT Communication Science Laboratories
yasuhiro.fujiwara.kh@hco.ntt.co.jp \\ Yasuhiro Fujiwara \\ yasuhiro.fujiwara.kh@hco.ntt.co.jp
}

keywords: deep learning, model compression, residual networks, deep neural networks

\begin{abstract}
Summary
Residual Networks with convolutional layers are widely used in the field of machine learning. Since they effectively extract features from input data by stacking multiple layers, they can achieve high accuracy in many applications. However, the stacking of many layers raises their computation costs. To address this problem, we propose Network Implosion, it erases multiple layers from Residual Networks without degrading accuracy. Our key idea is to introduce a priority term that identifies the importance of a layer; we can select unimportant layers according to the priority and erase them after the training. In addition, we retrain the networks to avoid critical drops in accuracy after layer erasure. Our experiments show that Network Implosion can, for classification on CIFAR10/100 and ImageNet, reduce the number of layers by $24.00 \% \sim 42.86 \%$ without any drop in accuracy.
\end{abstract}

\section{1.は じめに}

畳み込みニューラルネットワーク（Convolutional Neural Network, CNN) [LeCun 98] は画像認識分野におけ る様々なタスクにて高い精度を達成し, コンピュータビ ジョン及び機械学習コミュニティで広く使われているモ デルである. CNN は畳み込み層と呼ばれるレイヤーを重 ねた階層構造を持ったモデルであり, この階層構造を深 くすることによって精度を改善してきた. 1998 年, LeCun らは LeNet-5 と呼ばれる 5 層の CNN を用いて手 書き文字の分類を行った [LeCun 98]. 2012 年には 8 層 の AlexNet が ILSVRC の画像分類コンペティションを制 した [Krizhevsky 12]. 2014 年のコンペティションでは VGG Net[Simonyan 14] が 19, GoogleNet[Szegedy 15] が 22 のレイヤーを重ね，さらに精度を改善した。 2015 年のコンペティションでは Residual Network（ResNet） が 152 のレイヤーを重ね, この年のコンペティションを 制した $[\mathrm{He} 16 \mathrm{a}]$. 現在では ResNet は標準的な CNN ベー スのモデルの一つとして普及している.

CNN は深い階層構造により精度を改善する一方で, そ のレイヤー数の増加に伴い学習と推論にかかる計算コス トも増加した [Canziani 16]. 学習においては設備投資に よって計算リソースを増強し，アルゴリズムを修正する ことによって計算時間を大幅に短縮できることが明らか になってきた [Akiba 17]. しかし, 推論においては IoT
時代の到来に伴い，少ない計算リソース上で計算を行わ なければならない機会が増えている，例として，組み込 みシステム上での画像分類 $[\mathrm{Wu} \mathrm{16]}$, ポータブルデバイ ス上での文字認識 [Xiao 17]，モバイルデバイス上での音 声認識 [Schuster 10] などがあげられる．加えて，CNN のエネルギー消費量はメモリ消費量が大きいほど顕著に なる問題もサービスのランニングコストの面で好ましく ない [Han 15]. このような背景から, CNN の推論の計 算コストの削減は事業化の観点で大きな注目を浴びてい る研究分野の一つである.

階層構造を深くすることにより計算コストが増加する問 題に対し,レイヤー数を削減することで計算コストの削減 を試みるアプローチが提案されている. Veit らは ResNet の推論計算の途中で不要なレイヤーを動的にスキップする 手法を提案した [Veit 18]. Veit らのアイディアは, ResNet の全レイヤーは保持しておき, 入力データによって実行 するレイヤー数を変化させるというものである. しかし， 本枠組みでは ResNet の全レイヤーを保持する必要がある ため，メモリ消費量を削減することができない，反対に， どのレイヤーをスキップするかを決定するために追加の モジュールが必要となるため, メモリ消費量は増加する. Huang らは学習の時点で ResNet のレイヤー数を削減す る手法を提案した [Huang 18]. 本枠組みであれば推論計 算の時間を短縮しつつメモリ消費量も削減することがで きる.しかし，レイヤーを動的にスキップする手法群に対 
して，本手法群はレイヤーを完全に（静的に）削除してし まうため，精度を維持することが難しいという課題があ る. Ba らは蒸留 (knowledge distillation, teacher-student traininig）と呼ばれる手法を用い，レイヤー数の多い学 習済みモデルから新たにレイヤー数の少ないモデルを学 習できることを示した [Ba 14]. 蒸留は精度劣化を抑えつ つレイヤー数を削減できることが実験的に示され注目を 浴びている．計算コストを削減する観点からは，推論時 間とメモリ消費量の両方を削減できるため, レイヤーを 静的に削除する手法群と蒸留を用いた手法群がサービス 上では好ましいと言える。

本論文では，レイヤーを静的に削除する手法群の課題 である精度劣化を抑える手法（Network Implosion）を提 案し, 蒸留との比較実験を行う. 提案手法は ResNet の それぞれのレイヤーに対し，そのレイヤーの重要度を決 めるスカラー值を導入する。このスカラー值は他のパラ メータと同様に学習される，学習後はスカラー值を用い て重要でないレイヤーを特定し, 削除する. 精度の劣化 を防ぐため, 提案手法はレイヤーを削除した後の ResNet を再学習する。このようなパラメータの削除と再学習は 個々のパラメータの削除では有効であることが実験的に 知られているが [Han 15]，本論文ではレイヤーの削除に おいても有効であることを実験で示す．注意すべき点は， レイヤー削除における精度の維持では個々のパラメータ 削除 [Han 15] とは異なるハイパーパラメータ設定で再学 習を行う必要があるということである．実験においては CIFAR10/100, ImageNetのデータセットを用いた画像分 類のタスクにおいてレイヤー数を $57.14 \%$ ～76.00\% ま で削減した。これにより，推論の計算時間は $60.23 \%$ 〜 $76.69 \%$, モデルのパラメータ数は $69.82 \%$ ～93.15\%ま で削減された。

\section{2. 関 連 研 究}

ResNet のレイヤー数を削減する手法群は大きく 3 つに 分けられる.（1）推論計算の途中で不要なレイヤーを動 的にスキップする手法，(2) 学習の時点でレイヤー数を 静的に（完全に）削除する手法，（3）レイヤー数の多い 学習済みモデルから新たにレイヤー数の少ないモデルを 学習する手法 (蒸留) である.

（1）の動的なレイヤーのスキップの手法群として [Veit 18, Wu 18] があげられる. Veit らの手法は ResNet の推 論計算の途中で次のレイヤーを実行するか, スキップす るかを動的に決定する [Veit 18]. レイヤーを実行するか 否かの決定は各レイヤーにゲート関数を追加することで 実現している．前のレイヤーのシグナルをゲート関数に 入力し，1 を出力したときは次のレイヤーを実行し，0 出力したときは実行しない.このゲート関数自体もパラ メータを持っており, 学習フェーズでゲート関数のパラ メータも学習する. Wu らはゲート関数ではなく, ResNet
とは別にもう一つ別のニューラルネットワークを学習さ せ，そのニューラルネットワークにどのレイヤーを実行 するか否かを決定させる [Wu 18]. Wu らの手法は強化 学習ベースである.つまり，ニューラルネットワークは ResNet のどのレイヤーを実行させるかをアクションとし てとることができ，実際に実行した際の精度を報酬とす ることで, 精度劣化を抑えつつ実行するレイヤー数を削 減しようとする. しかし, この手法群は平均の推論時間 は削減できるが, 追加のゲート関数やニューラルネット ワークを必要とするためメモリ消費量が増加するという 問題がある.

（2）の静的なレイヤー削除の手法群として [Huang 18, Yu 18] があげられる. Huan らはレイヤーの出力に学習可 能なスカラー值を乗じるモデルを用いる [Huang 18]. こ のスカラー值に L1 正則化をかけることで, 学習中に多く のスカラー值を 0 にする [Fujiwara 16a, Fujiwara 16b, Ida 19]. スカラー值が 0 に対応するレイヤーは実行されて いない状態と同等であるため, そのようなレイヤーを完 全に削除することができる. Yu らは各レイヤーの出力に 閾值を設定し，閾値を下回ったレイヤーを削除する [Yu 18]. これらの手法は（1）の手法群と異なり, 完全にレ イヤーを削除するため推論計算の時間とメモリ消費量を 同時に削減することができる. しかし, 完全にレイヤー を削除するため, 精度を維持することが難しい. 実際に, これらの手法は CIFAR10 などのトイデータでは精度を 維持できることが実験的に示されているが, ImageNet な どの実データでは精度を維持できていない. 加えて, こ れらの手法は正則化の強さを調整するハイパーパラメー タや閾值などの連続值のハイパーパラメータをチューニ ングする必要がある.つまり, 所望のレイヤー数を持つ ResNet を得るために連続值のハイパーパラメータを調整 しなければならなくなり, チューニングコストが増加す る. 本論文の提案手法である Network Implosion は本手 法群に位置付けられるが, ImageNet の実データにおいて も精度劣化を起こさず, チューニングコストの高い連続 值の追加ハイパーパラメータも有しない。

（3）は蒸留 [Ba 14, Hinton 15] と呼ばれるテクニック を利用する．蒸留は学習済みのニューラルネットワーク （教師）の情報を活用し, 別のニューラルネットワーク（生 徒）を効率的に学習する枠組みであり, teacher-student 学 習とも呼ばれる. 具体的には, 教師となるモデルの出力 する確率分布と, 生徒となるモデルの出力する確率分布 が近くなるような制約を学習時に課すことで生徒の学習 を補助する. Ba らは教師となるモデルよりも小さいモデ ルを生徒として用いた場合でも精度を維持できることを 実験で示した。加えて, teacher-student 学習は所望のレ イヤー数を直接設定できるため，ハードウェアのメモリ 制約がある場合にも使いやすい. 以来, 蒸留は様々なモ デルの圧縮で使われている [Chen 17, Mishra 17].

本研究で扱うレイヤーレベルのパラメータ削除に対し, 


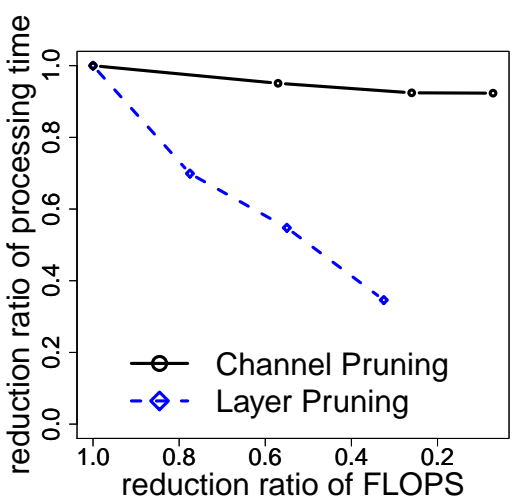

図 1 バッチサイズ 1 における 56 層 ResNet に対するチャネルレベ ルとレイヤーレベルのパラメータ削除の FLOPS と実行時間 の削減率の関係.

チャネルレベルのパラメータ削除も研究されてきた $[\mathrm{He}$ 17, He 18, Li 16, Liu 17, Liu 19, Luo 17, Yang 18]. チャ ネルレベルのパラメータ削除を用いることで各レイヤー の行列演算におけるパラメータ側の行列のサイズを削減 することができる。これにより，チャネルが十分に削除で きればモデルの軽量化と推論の高速化を期待できる.し かし，パラメータ側の行列サイズが小さい場合, FLoating point number Operations Per Second（FLOPS）の観点か らは演算回数を大きく下げられても，実際の実行時間を あまり短縮できない場合がある．代表的な例としてバッ チサイズが小さく，パラメータ側だけでなく入力側の行 列も小さくなることにより GPU の利用効率が下がる場合 があげられる [Bianco 18]. こうしたバッチサイズを小さ くする設定は, 例えば映像をリアルタイムで処理する必 要のあるアプリケーションやメモリ制約のある環境下で 起こりうる.これに対し，レイヤーレベルのパラメータ 削除は各レイヤーのパラメータ側の行列サイズを削減し ないため，バッチサイズが 1 の場合でも高い GPU 利用効 率を期待できる. 図 1 に実際にバッチサイズが 1 の場合 の GeForce GTX $1080 \mathrm{Ti}$ 上での FLOPS と実行時間の削 減率の関係を示す。本図は 56 層の ResNet に対してチャ ネルレベルとレイヤーレベルのパラメータ削除を，削除 するパラメータの割合を変化させながら適用し推論（予 測）計算の FLOPS と平均実行時間の削減率の関係を示 したものである. なお，推論計算に用いたデータセット は CIFAR10 であり, 削除するパラメータの選択はチャ ネルレベル・レイヤーレベル共にランダムに行っている. チャネルレベルのパラメータ削除では FLOPS を 7\%まで 削減したとしても，実際の実行時間は 92\%までしか削減 できていない。これに対し，レイヤーレベルのパラメー タ削除は FLOPS を $32 \%$ まで削減した時点で実行時間も 34\%まで削減できている。レイヤーレベルのパラメータ 削除は, 上記のようなチャネルレベルのパラメータ削除 ではハードウェアの利用効率が下がってしまう場合に効 果を期待できる。ただし，レイヤーレベルのパラメータ

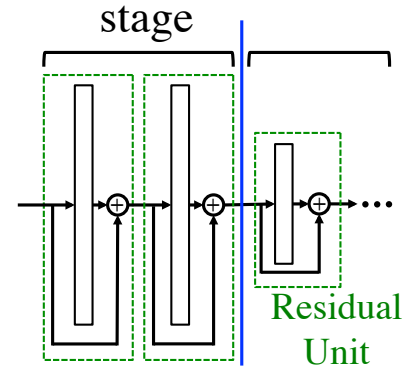

図 2 ResNet のステージとステージの変わり目の様子.

削除はこれまで述べてきたように精度の維持が難しいと いう課題がある．実際にチャネルレベルのパラメータ削 除の近年の手法は ILSVRC12 の ImageNet のデータセッ トを用いた 50 層の ResNetに対し, Top-5 Accuracy の 低下を $1 \%$ 以内に抑えつつ FLOPS を約 $50 \%$ まで削減し ているが [Peng 19]，レイヤーレベルのパラメータ削除は FLOPS を約 50\%まで削減しようとすると $2 \%$ 以上 Top-5 Accuracy が低下してしまう [Huang 18]. 本研究は上述 のようなレイヤーレベルのパラメータ削除における精度 維持の困難さを課題とし取り組むものである.

\section{3. 前 準 備}

本章では画像認識分野などで広く使われている CNN の一種である ResNetの説明を行う．ResNet は Residual Unit と呼ばれるブロックを複数重ねることで深い構造を 実現する [He 16a]. それぞれの Residual Unit は複数の 畳み込み層で構築されているため, Residual Unit を重ね ることで畳み込み層を重ねることができる，Heら $[\mathrm{He}$ 16b]によると, $l$ 番目の Residual Unit は次のように計算 される :

$\mathbf{x}_{l+1}=\mathbf{x}_{l}+F\left(\mathbf{x}_{l}\right)$,

ここで, $\mathrm{x}$ は $l$ 番目の Residual Unit への入力信号である. $F(\cdot)$ は畳み込み層，バッチ正規化（batch normalization） [Ioffe 15], ReLU (Rectified Linear Unit) [Krizhevsky 12] 活性化関数から構成されるモジュールである。したがっ て, Residual Unit は入力信号を恒等写像と非線形写像に 通し，その結果を加算するユニットと言える.

ResNet には Residual Unit の他に，ステージ [Greff 16] と呼ばれる構造がある。1つのステージには各次元の大 きさが等しい複数の Residual Unit が重ねられる。この ステージを複数重ねることで ResNet は構成される．ス テージが変わる場所では, ダウンサンプリングやチャネ 儿数を増やす操作が行われる.つまり，図 2 に示すとお り，ステージの変わり目で Residual Unit の次元の大きさ が変更される。 


\section{4. 提 案 手 法}

本章では ResNet のレイヤー数を静的に（完全に）削除 しつつ, 精度の劣化を抑える手法（Network Implosion） を提案する. 提案手法はレイヤーの削除と再学習を繰り 返し，徐々にResNet のレイヤー数を削減する。本章で は最初に削除対象となるレイヤーの選択方法と再学習の アイディアを導入した後，それらを利用した具体的なア ルゴリズムを説明する.

\section{$4 \cdot 1$ 手 法 概 要}

\section{$\S 1$ 削除対象となる Residual Unit の特定}

ResNet から Residual Unit を削除するためには削除対 象となる Residual Unit を特定する必要がある. 先行研究 では精度を大幅に劣化させる Residual Unit が存在するこ とが明らかになっている [Greff 16].こうした Residual Unit を削除してしまうと再学習による精度の回復が難し くなると考えられる．そこで，精度に対する影響が少な いResidual Unit を削除対象とする必要がある.

この問題に対し，本手法は Residual Unit の重要度を表 す変数を導入する.この変数は他のパラメータ同様に学習 データから学習可能なスカラー值であり，1 つの Residual Unitにつき 1 つ導入される. 具体的には, 式 (1) 内の $F(\cdot)$ の重要度を学習する. 重要でない $F(\cdot)$ を特定した後はそ の $F(\cdot)$ を削除する.これにより，次の Residual Unit へ の入力は $\mathbf{x}_{l+1}=\mathbf{x}_{l}$ となるため, 実質 Residual Unit その ものを削除したことと同様の効果を得る，重要度を表す 変数は Residual Unit の式 (1) に対して以下のように導入 される :

$\mathbf{x}_{l+1}=\mathbf{x}_{l}+w_{l} F\left(\mathbf{x}_{l}\right)$.

ここで， $w_{l}$ は誤差逆伝播によって学習可能なスカラー 值をとる変数である. $w_{l}$ は $F(\cdot)$ の上に重ねられたスカ ラー值をかけるレイヤーとみなせるため, 深層学習フレー ムワークを用いれば誤差逆伝播等の計算も容易に実装す ることができる．学習の結果, $w_{l}$ の絶対值 $\left|w_{l}\right|$ が小さ くなった場合, $F(\cdot)$ の出力は小さくスケーリングされる と考えられるため, そのような $F(\cdot)$ は出力に与える影 響が小さいとみなせる。したがって，本手法では $\left|w_{l}\right|$ を Residual Unit の重要度とみなし, $\left|w_{l}\right|$ が小さい Residual Unit を削除対象とする.

注意すべき点は，ResNetには最後まで削除すべきでな い Residual Unit が存在するという点である．[Greff 16] によるとステージが変わった直後の Residual Unit は削 除すると精度を大きく劣化させる．これは，ステージの 変わり目でダウンサンプリングやチャネル数の増加が行 われ，新しい中間表現が獲得されるためであるとされる （図 1).このような Residual Unit は精度の維持にとって 重要であるため, 本手法ではステージが変わった直後の Residual Unit は削除の対象とせず，通常の式 (1) を用い

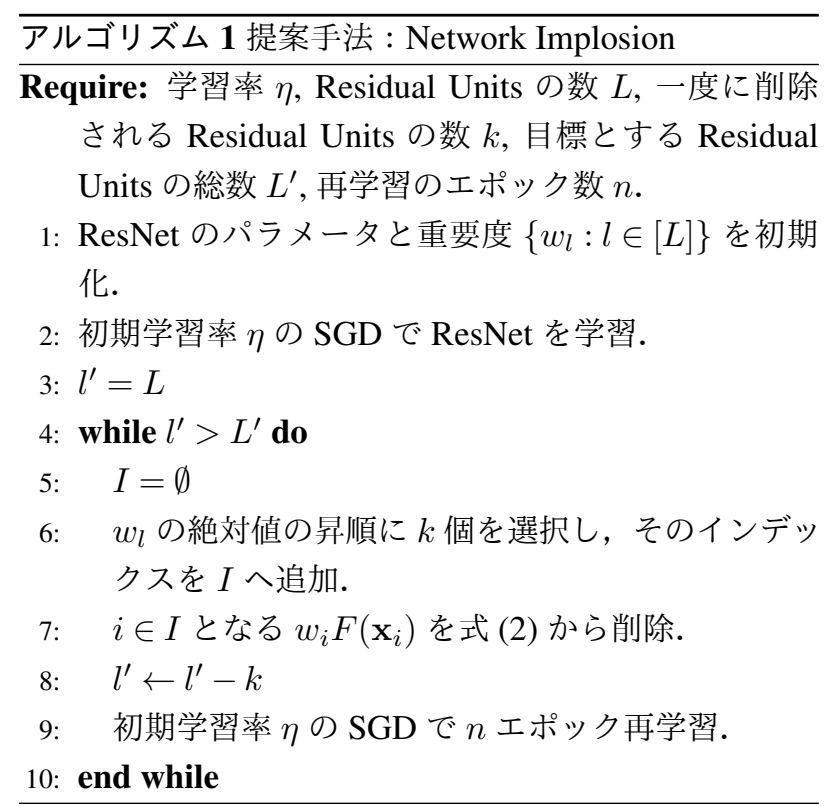

る. 本アイディアは追加のパラメータ（重要度）を要す るが, このパラメータはベクトルやテンソルではなくス カラーとなるため，モデルサイズにはほとんど影響がな いものとみなせる.

\section{\$2 Residual Unit $の$ 削除と再学習}

[Veit 16] らは ResNet から複数の Residual Unit を一度 に削除すると精度が落ちやすいことを示した。この結果 を受け, 本手法は Residual Unit の削除と再学習を交互に 行い, 一度に多くの Residual Unit を削除するのではな く，徐々に少しずつ Residual Unitを削除していく形式を とる.

[Cheng 18] はモデルのパラメータ削除の手法を要素/ベ クター/カーネル/グループ/フィルターレベルと分類した. 本手法は上述のカテゴリにはないレイヤーレベルでのパ ラメータ削除である. 一度の削除で最も多くのパラメー タを削除するため, これに伴い再学習によるモデルの修正 量も大きくなると考えられる. したがって再学習において は，パラメータを大きく更新するために Stochastic Gradient Descent などの学習アルゴリズム [Ida 17, Kingma 14, Robbins 51] の学習率を大きく設定する. 具体的には, 最初の学習で用いた学習率と同じ大きさの学習率を再学 習にも適用する. 個々のパラメータ削除における再学習 [Han 15] では小さい学習率を用いるため, このような学 習率の設定は対照的な設定であると言える.

$4 \cdot 2$ アルゴリズム

アルゴリズム 1 に提案手法である Network Implosion の疑似コードを示す. 本アルゴリズムでは, Stochastic Gradient Descent などの学習アルゴリズムの学習率を $\eta$, 最初の ResNet の Residual Units の総数を $L$, 一度に削 除される Residual Units の数を $k$, 目標とする Residual Units の総数を $L^{\prime}$, 再学習の学習エポック数を $n$ として表 記する.これらは本アルゴリズムにおける主要なハイパー 
パラメータである. 本アルゴリズムでは，まず Residual Unit の重要度を表す $w_{l}$ を全ての Residual Unit につい て初期化する（行番号 1）。初期化は例えば $[-1,1]$ の 区間の一様乱数などを用いる. 次に学習アルゴリズムを 用いて ResNet を学習する（行番号 2）。本アルゴリズ ムは徐々に Residual Unit を削除していくため, 現在の Residual Unit 数を表す $l^{\prime}$ を導入する（行番号 3）. その 後に Residual Unit と再学習を繰り返すループヘ入る（行 番号 4〜10).このループは目標とする Residual Unitの 数 $L^{\prime}$ まで Residual Unit が削除できたら停止するが, 精 度が劣化した時点で停止するような条件に変更してもよ い（行番号 4）。ループ内では削除対象となる Residual Unitのインデックスの集合を表す $I$ が設定される（行番 号 5). 重要度 $w_{l}$ に従い重要でないと判断される $k$ 個 の Residual Unit のインデックスを $I$ に追加する（行番号 6).この $I$ に含まれるインデックスに対応する $w_{i} F\left(\mathbf{x}_{i}\right)$ を式 (2) から削除し, レイヤーの削除を行う（行番号 7). Residual Unit の削除に伴い, 現在の Residual Unit 数 $l^{\prime}$ を更新する (行番号 8). Residual Unit を削除した後の ResNetに対し, $n$ エポックの再学習を行う（行番号 9). このとき, 学習アルゴリズムの初期の学習率 $\eta$ の初期值 は行番号 2 で用いた初期の学習率と同様のものを用いる.

\section{5. 実験}

本章では提案手法を精度と推論フェーズの計算コスト の観点から評価する．本評価では画像認識分野における 標準的なタスクである画像分類で評価を行う.

\section{$5 \cdot 1$ 設定 \\ $\$ 1$ データセット}

本評価ではデータセットとして CIFAR10/100[Krizhevsky 09], 及びILSVRC2012の ImageNet のデータセット [Russakovsky 15] を使用した. CIFAR10/100 はそれぞれ 10, 100 の分類クラスを持つ画像のデータセットである. 画像 サイズは $32 \times 32 \times 3$ である. ImageNet は 1000 の分類 クラスを持つデータセットであり, 画像サイズは $224 \times$ $224 \times 3$ である. 本実験では [Szegedy 15] に従い, 学習· テスト時に画像に対して $224 \times 224 \times 3$ の single centercropping を施す。また, [Krizhevsky 12, Szegedy 15] と 同様に, 学習時には data augmentation として color, scale aspect ratio augmentationを施す.

$\$ 2$ モデル

本評価では多くの画像分類タスクで用いられる ResNet[He 16b] をモデルとして使用する. [He 16b] に従い, それぞ れの Residual Unitにはボトルネック構造を採用する.そ れぞれの Residual Unit はバッチ正規化とセットになった 3 層の畳み込み層を持ち, 活性化関数は ReLU 活性化関 数を用いる. ステージの数は CIFAR10/100 で 3 つ, ImageNet で 4 つをす. この結果, [He 16a] と同様に層数
は CIFAR10/100 で 56 層, ImageNet で 50 層となる， ス テージの変わり目において Residual Unit の次元を変化さ せる際には projection shortcut[He 16b] を用いる.

\section{$\S 3$ ハイパーパラメータ}

ハイパーパラメータについては画像分類で標準的に用 いられる [He 16b] と fb.resnet.torch*1に従い設定した. 学 習アルゴリズムはモーメンタム付き SGD を用い, その モーメンタム係数は 0.9 , 初期学習率は 0.1 とした. トー タルの学習エポック数は 200 とした. CIFAR10/100で は学習率は 81 エポック目と 122 エポック目に 0.1 倍し た. ImagaNetでは学習率は 30 エポック毎に 0.1 倍した. バッチサイズは CIFAR10/100 では 128, ImagaNet では 512 とした. 荷重減衰の係数は 0.0001 とし, パラメータ は [He 15]に従い初期化した。

\section{$\$ 4$ 比較手法}

比較手法は通常の ResNet と蒸留を用いたモデル圧縮 (teacher-student 学習) [Ba 14, Hinton 15] とした. 関連研 究の章で述べた通り, teacher-student 学習は動的にレイ ヤーをスキップする手法群や静的にレイヤーを削除する手 法群と比して精度を維持しつつ計算コストを削減しやす いことが経験的に示されている. 加えて, teacher-student 学習は他の手法群とは異なり直接レイヤー数を指定するこ とができるため，ハードウェアのメモリ制約がある場合な どにも使用しやすく, 本論文のモチベーションに沿うべー スラインである．教師モデルとして CIFAR10/100 では 56 層, ImageNet では 50 層の ResNet を用いた. teacherstudent 学習にはハイパーパラメータとして温度とクロ スエントロピーの重みがある [Hinton 15]. それぞれ CIFAR10/100 では 4, 0.9, ImageNetでは 1, 0.5 を採用 した.

\section{$\$ 5$ 提案手法}

提案手法の ResNet では式 (2) の Residual Unit を用い る.ただし，ステージの変わり目で Residual Unit の次 元が変化する部分では式 (1) で表される通常の Residual Unit を用いる.これはResNet ではステージの変わり目 で新たな特徵マップが生成され，同一ステージ内では特 徵マップの微調整が行われるのみであるという [Greff 16] の研究結果に基づく. [Greff 16]によると, ステージの 変わり目で次元が変化する Residual Unit は特徵抽出にお いて重要な役割を持つため, 本論文の提案手法ではこの Residual Unit は削除の対象としない. 提案手法では層の 削除と再学習を繰り返すが，一度に削除される層の数は 少ない方が精度劣化を抑えられるという [Veit 16] らの実 験結果に基づき，一度に削除する Residual Unit は 1 つ $(k=1)$ とした. $k$ を変化させたときの性能の変化につい ては 5.4 節で示す. 1 つの Residual Unit は 3 層の畳み込 み層を持つため, 一度の Residual Unit の削除で 3 層削除 されることになる. 再学習における初期学習率は 0.1 と し，エポック数は 60 とした。学習率は 20 エポック目と

\footnotetext{
*1 https://github.com/facebook/fb.resnet.torch
} 


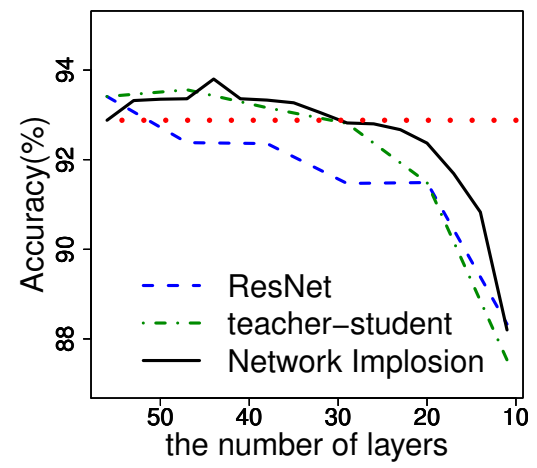

(a) CIFAR10

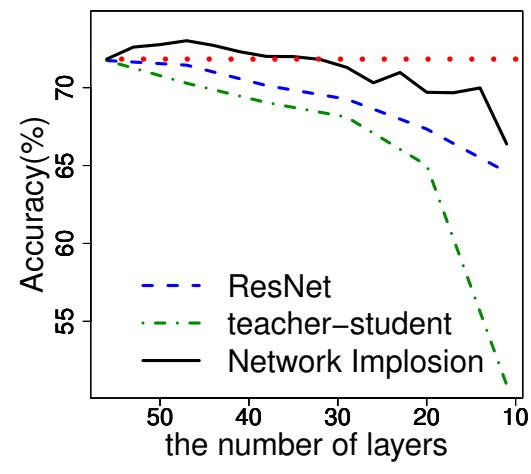

(b) CIFAR100

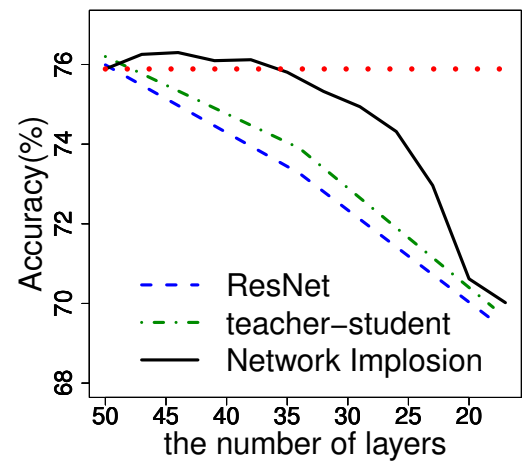

(c) ImageNet

図 3 CIFAR10/100, ImageNet における精度とレイヤー数. 赤い点線は提案手法の初期の精度を表す. 提案手法 はレイヤーを削除しても精度を維持しやすいことがわかる.

表 1 レイヤー削除前と後の各ステージに残存するレイヤー数の比較. ステージ 1 のレイヤー数が最も少なくな ることがわかる.

\begin{tabular}{ccccccc}
\hline \multirow{2}{*}{ データセット } & 層数 & 精度 $(\%)$ & $\begin{array}{c}\text { ステージ1の } \\
\text { 層数 }\end{array}$ & $\begin{array}{c}\text { ステージ2の } \\
\text { 層数 }\end{array}$ & $\begin{array}{c}\text { ステージ3の } \\
\text { 層数 }\end{array}$ & $\begin{array}{c}\text { ステージ4の } \\
\text { 層数 }\end{array}$ \\
\hline \multirow{2}{*}{ CIFAR10 } & 56 & 92.88 & 18 & 18 & 18 & - \\
\cline { 2 - 8 } & $\mathbf{3 2}$ & $\mathbf{9 3 . 0 5}$ & $\mathbf{3}$ & $\mathbf{1 5}$ & $\mathbf{1 2}$ & - \\
\hline \multirow{2}{*}{ CIFAR100 } & 56 & 71.83 & 18 & 18 & 18 & - \\
\cline { 2 - 8 } & $\mathbf{3 5}$ & $\mathbf{7 1 . 9 9}$ & $\mathbf{3}$ & $\mathbf{1 2}$ & $\mathbf{1 8}$ & - \\
\hline \multirow{2}{*}{ ImageNet } & 50 & 75.89 & 9 & 12 & 18 & 9 \\
& $\mathbf{3 8}$ & $\mathbf{7 6 . 1 2}$ & $\mathbf{6}$ & $\mathbf{6}$ & $\mathbf{1 5}$ & $\mathbf{9}$ \\
\hline
\end{tabular}

40 エポック目に 0.1 倍した. 再学習のエポック数 $n$ は才 リジナルの学習エポック数と同様の值を設定することを 推奨するが, 本研究では $n$ をオリジナルの学習エポック 数より小さく設定しても精度をある程度維持できること を 5.4 節で確認する.

\section{$5 \cdot 2$ 精 度}

本章ではレイヤー数を変化させたときのテストデータに 対する画像分類の精度を評価する，ただし， ImageNetで はテストデータが存在しないため, コンピュータビジョン 分野での標準的な評価方法に倣い, バリデーションデータ の精度を評価する，比較手法は通常の ResNet と teacherstudent 学習を用いた ResNetである. CIFAR10/100では レイヤー数を 56 層から 11 層まで変化させる. このとき, 1 ステージにつき $18,15,12,9,6,3$ 層を有する 6 つの ResNetを用いた. ImageNetにおいては提案手法は 50 層 から 17 層まで変化させ, 通常の ResNet と techer-student 学習ではベンチマークで広く用いられる 50 層, 34 層, 18 層のモデルを比較対象として学習させた.

図 3 にレイヤー数と画像分類の精度のグラフを実駼結 果として示す. 青の破線はレイヤー数の異なる各 ResNet の精度を, 緑の鎖線は teacher-student 学習によって学習 された異なるレイヤー数の生徒モデルの ResNet の精度 を示す. 黒線は提案手法によってレイヤーを削除していっ た際の各 ResNet の精度を，赤の点線は提案手法の初期
の精度を示す．提案手法はレイヤーを削除しつつ，赤の 点線で表される初期の精度を維持していることがわかる. 最終的に, 提案手法は CIFAR10/100 と ImageNetにおい てそれぞれ 32，35，38 層まで精度を維持しながら層数を 削減できた。これらは黒線と赤の点線の交差点に相当す る層数である.つまり, CIFAR10/100 と ImageNetにお いてそれぞれ $42.86 \%, 37.50 \%, 24.00 \%$ のレイヤーを削 除できたことになる. 青の破線と黒線を比較すると, 通 常の ResNet のレイヤー数を変化させて学習した場合よ りも, 徐々にレイヤーを削除して学習した ResNet の方が 精度が高いことがわかる. 緑の鎖線と黒線を比較すると, CIFAR10 においては teacher-student 学習は提案手法と ほぼ同様の精度を達成しているが, CIFAR10/ImageNet においては精度を維持できていない。一方で，提案手法 は CIFAR100 と ImageNetにおいてもレイヤー数を削減 しながら精度を維持できていることがわかる.

表 1 は精度劣化が起きていない最小の ResNetについ て, 各ステージで残ったレイヤー数を示したものである. 表 1 によると, 提案手法は各ステージで異なるレイヤー 数のアーキテクチャを発見できていることがわかる. 既 存の ResNet の設定では各ステージで同じレイヤー数を 設定するケースが多いため, これは提案手法の一つの利 点と言える. 本結果によると, 1 番目のステージ, つまり 入力に最も近いステージのレイヤー数が最も少なくなっ ていることがわかる. [Greff 16]によると， 1 番目のス 
表 2 推論時における計算コスト. 提案手法によって得られた精度劣化を起こさない最小の ResNet で比較. 提 案手法は精度劣化を起こさずに全ての計算コストの指標を改善した。

\begin{tabular}{ccccccc}
\hline データセット & 層数 & 精度 $(\%)$ & MAC の回数 & 順伝播 $(\mathrm{msec})$ & 逆伝播 $(\mathrm{msec})$ & パラメータ数 \\
\hline \multirow{2}{*}{ CIFAR10 } & 56 & 92.88 & $8.19 \times 10^{7}$ & 6.584 & 12.93 & $585.9 \mathrm{~K}$ \\
\cline { 2 - 7 } & $\mathbf{3 2}$ & $\mathbf{9 3 . 0 5}$ & $\mathbf{4 . 9 9} \times \mathbf{1 0}^{\mathbf{7}}$ & $\mathbf{3 . 9 7 0}$ & $\mathbf{7 . 7 2 1}$ & $\mathbf{4 0 9 . 1 K}$ \\
\hline \multirow{2}{*}{ CIFAR100 } & 56 & 71.83 & $8.65 \times 10^{7}$ & 6.203 & 13.36 & $613.6 \mathrm{~K}$ \\
\cline { 2 - 7 } & $\mathbf{3 5}$ & $\mathbf{7 1 . 9 9}$ & $\mathbf{5 . 4 4} \times \mathbf{1 0}^{\mathbf{7}}$ & $\mathbf{4 . 3 5 0}$ & $\mathbf{8 . 0 7 5}$ & $\mathbf{5 5 5 . 3 K}$ \\
\hline ImageNet & 50 & 75.89 & $4.11 \times 10^{9}$ & 29.95 & 59.51 & $25.55 \mathrm{M}$ \\
\cline { 2 - 7 } & $\mathbf{3 8}$ & $\mathbf{7 6 . 1 2}$ & $\mathbf{3 . 2 3} \times \mathbf{1 0}^{\mathbf{9}}$ & $\mathbf{2 2 . 9 7}$ & $\mathbf{4 6 . 5 3}$ & $\mathbf{2 3 . 8 0 M}$ \\
\hline
\end{tabular}

テージの最初の Residual Unit は単純な中間表現を出力 し，かつそれはそのステージの最終的な中間表現と類似 した中間表現となる。したがって，1 番目のステージは Residual Unit を少なくしたとしても精度への影響は少な いと言える. 1 番目のステージの Residual Unit を積極的 に削除するという表 1 の結果は [Greff 16] の主張を支持 するものである.

\section{$\mathbf{5} \cdot \mathbf{3}$ 計 算 コスト}

本章では提案手法によって学習される, 精度を維持でき る最小の ResNet の計算コストの評価を行う。評価指標と して積和演算の回数を表す MAC (multiply-accumulate), 推論計算で用いられる順伝播の実行時間, 逆伝播の実行 時間, モデルのパラメータ数を用いる. MAC は畳み込 み層と全結合層における主要な計算である。実行時間は 100 回の実行時間の平均を評価する。学習における実験 設定は前の章と同様とした。提案手法は CIFAR10/100 と ImageNet においてそれぞれ 32，35，38 層まで精度を維 持しながら層数を削減できたため, これらのモデルを前 述の評価指標で評価した。

表 2 に評価結果を示す. MAC の回数に関しては CIFAR10/100 と ImageNet においてそれぞれ 60.93\%，62.89\%， $78.59 \%$ まで削減できていることがわかる. 順伝播の実行時 間はそれぞれ 60.23\%，70.13\%，76.69\%まで削減できた。 逆伝播の実行時間はそれぞれ 59.71\%，60.44\%，78.19\% まで削減できた. パラメータ数に関しては精度劣化なしで それぞれ 69.82\%，90.50\%，93.15\%まで削減できた。こ れらの実験結果は, 提案手法がメモリ消費量を増加させ ることなく, 精度劣化なしに推論計算を高速化している ことを示している. 関連研究の章にて, 動的なレイヤー スキップの手法群では精度は維持しやすいがメモリ消費 量が増加し, 静的なレイヤー削除の手法群ではメモリ消 費量は削減できるが精度は劣化することを述べた。この ため, 本実験結果から提案手法は両者の長所を持つ手法 となっていることがわかる.

\section{$5 \cdot 4$ ハイパーパラメータへの依存性}

本章では提案手法のハイパーパラメータである再学習 のエポック数と一度に削除する Residual Unit 数の精度と の関係を調べる.

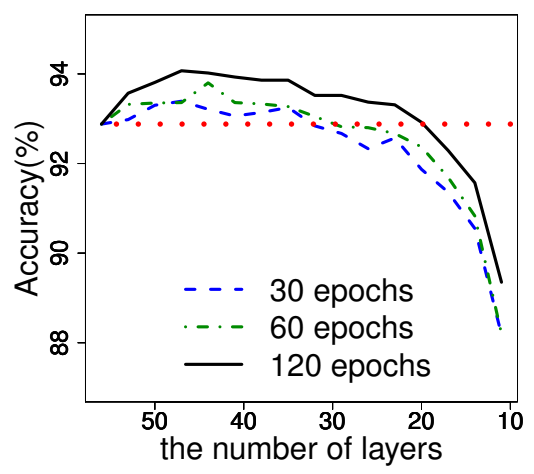

図 4 CIFAR10 で学習された 56 層の ResNet に提案手法を適用し, 再学習のエポック数を $30,60,120$ としたときの精度とレイ ヤー数の関係. エポック数が大きいと精度を維持しやすいが, エポック数が小さい場合でもある程度精度を維持できること がわかる。

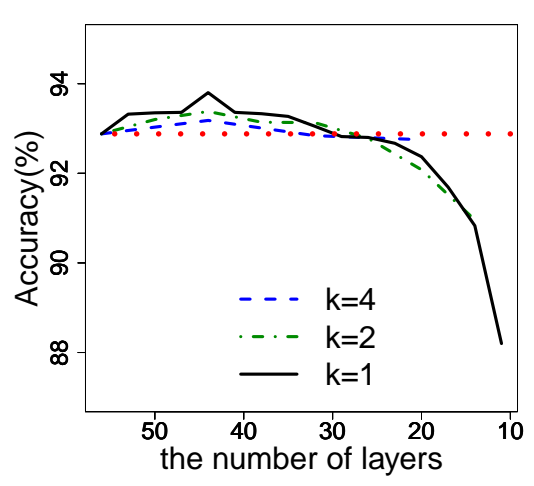

図 5 CIFAR10 で学習された 56 層の ResNet に提案手法を適用し, 一度に削除する Residual Unit 数 $k$ を 1,2,4 としたときの精 度とレイヤー数の関係. $k$ が小さいほどトレードオフが改善 できているが, $k$ が大きい場合も初期精度をある程度維持で きることがわかる.

CIFAR10 で学習された 56 層の ResNetについて, 再 学習のエポック数を $30,60,120$ としたときの精度とレイ ヤー数の関係を図 4 に示す. それぞれのエポック数で初 期の精度を維持できた最小の ResNet は 30 エポックで 35 層, 60 エポックで 32 層, 120 エポックで 20 層であった. エポック数が大きいほど精度とレイヤー数のトレードオ フを改善できることがわかる．本手法では 30 エポック 


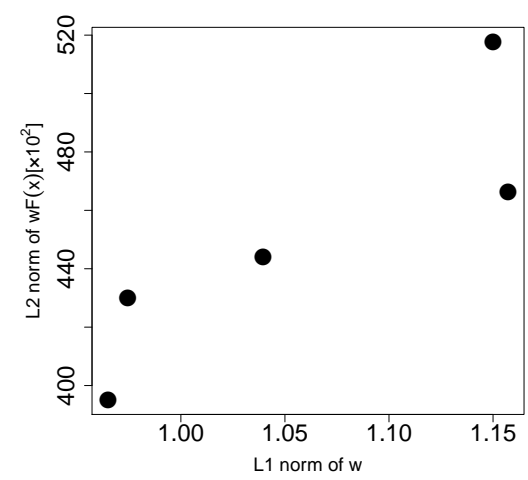

(a) ステージ 1

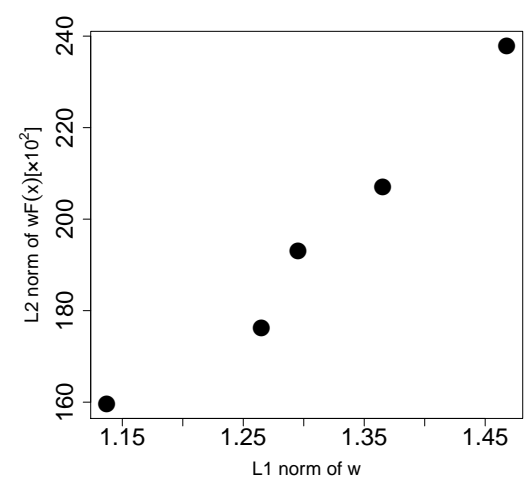

(b) ステージ 2

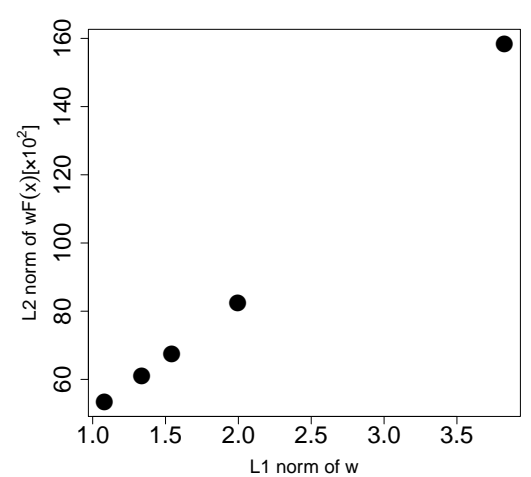

(c) ステージ 3

図 6 CIFAR 10 で学習された 56 層 ResNet の各ステージの重要度 $w_{l}$ の絶対值とスケーリングされた出力 $w_{l} F\left(\mathbf{x}_{l}\right)$ の大きさ（L2ノルム）の平均の散布図. 重要度が小さいほど出力のシグナルは小さくなることがわかる.

で再学習した場合でも精度をある程度維持しながらレイ ヤーを削除できている.これは, 前の再学習で得られたパ ラメータを次のレイヤー削除後のモデルの再学習の初期 值として使うため，最初からある程度高い精度を持った モデルから再学習を開始できるためであると考えられる.

図 5 は再学習のエポック数を 60 で固定し, 一度に削除 する Residual Unit 数 $k$ を 1, 2, 4 としたときの精度とレ イヤー数の関係を示したものである.それぞれの $k$ の設 定で得られる ResNet のレイヤー数は $k=1$ で 56, 53, 50, $47,44,41,38,35,32,29,26,23,20,17,14,11, k=2$ で $56,50,44,38,32,26,20,14, k=4$ で 56, 44, 32, 20 であることに注意する. 図より $k$ が小さいほど再学習に よる精度の向上幅が大きいことがわかる。これは [Veit 16] らが示したように，一度に削除する Residual Unit 数 が少ないほど精度劣化が小さくなり，その結果 $k$ が小さ い場合は最初からある程度高い精度から再学習を開始で きるためであると考えられる。また，初期の精度が維持 できた最小の ResNet は $k=1$ で 32 層, $k=2$ で 32 層, $k=4$ で 44 層となった. $k=4$ のときのみ 32 層まで精 度を維持できなかったが，この 32 層の ResNet の精度は $92.84 \%$ であり, 初期の精度 $92.88 \%$ とほぼ同等の精度を 達成している.

\section{5 .5 重要度によるスケーリングの効果}

提案手法では Residual Unit の重要度の指標として $w_{l}$ の絶対值を用いている. つまり， $w_{l}$ の絶対值が小さい と $F\left(\mathbf{x}_{l}\right)$ の出力が小さくスケーリングされ, その結果 $w_{l} F\left(\mathbf{x}_{l}\right)$ が小さくなり，全体の出力に与える影響が少な くなるという考えが背景にある。これを確かめるため, CIFAR10 で学習した 56 層の ResNet の $w_{l}$ の絶対值と バリデーションデータ上での $w_{l} F\left(\mathbf{x}_{l}\right)$ の大きさ（L2） ルム）の平均の関係をステージ毎に可視化した．図 6 に その結果を示す。この図より, $w_{l}$ の絶対值が小さいほど $w_{l} F\left(\mathbf{x}_{l}\right)$ の L2 ノルムが小さくなっていることがわかる. したがって， $w_{l}$ によって $F\left(\mathbf{x}_{l}\right)$ が小さくスケーリングさ

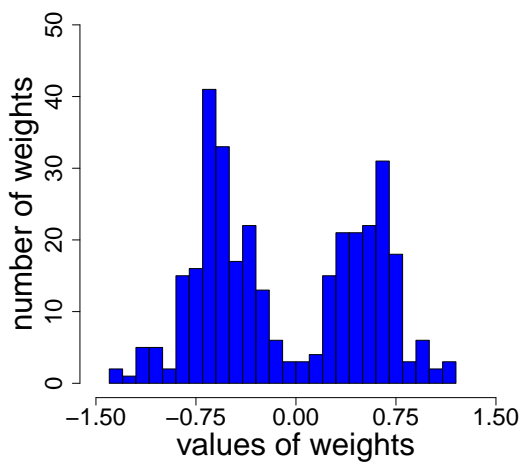

図 7 CIFAR10 で学習された 1001 層 ResNet の Residual Unit の重 要度のヒストグラム。

れていると言えるため, $w_{l}$ の絶対值は経験的に Residual Unit の重要度の指標として使えると言える。

\section{5 .6 重要度の分布}

本章では提案手法に導入した重要度 $w_{l}$ の性質を調べ るため, 1001 層の ResNet を CIFAR10 のデータセット で学習し，その Residual Unit の重要度 $w_{l}$ の分布を可視 化した。図 7 は CIFAR10 で学習された 1001 層 ResNet の Residual Unit の重要度 $w_{l}$ の值のヒストグラムである. 提案手法は $w_{l}$ を $[-1,1]$ の一様乱数で初期化するが, 学 習を行うことでこれらが 2 つのガウス分布を混合したよ うな形状となることがわかる．要素レベルのパラメータ 削除では，学習済みの個々のパラメータのヒストグラム は平均 0 付近をとる単峰の正規分布となることが知られ ている [Han 15]. 要素レベルのパラメータ削除において はこのパラメータの絶対值を重要度として用いるため，0 付近が最頻值となり, 多くのパラメータが重要でないと 判断される. 0 に近いパラメータは削除しても出力に与 える影響が少ないと考えられ，[Han 15] らのように小 さな学習率で再学習を行えば精度を維持できる。これに 
対し, レイヤーレベルのパラメータ削除の $w_{l}$ のヒスト グラムは図 7 に示したとおり，0 付近で対称な 2 つ正 規分布のような形状となる。重要度として用いる絶対值 をとるとその最頻值は 0 ではなく 0.7 付近となる. つま り，提案手法でレイヤーを削除する場合，ある程度大き な重要度を持つレイヤーも削除対象としなければならな いケースが発生する.この場合, 精度を維持するために モデルを大きく修正する必要があるため, レイヤーレベ ルのパラメータ削除では本論文で用いているような大き な学習率を再学習にて設定する必要があると考えられる.

\section{6. 結 論}

本論文では推論の計算コストを削減するため, 精度劣 化を抑えつつ ResNet のレイヤー数を削減する手法を提 案した。提案手法は重要でない Residual Unit を特定す るためのスカラーのパラメータを持っており，これに従 い Residual Unit が選択・削除される. 削除後は大きな 学習率で再学習を行うことで劣化した精度を補う. CIFAR10/100, ImageNet を用いた画像分類タスクでは, 既 存手法と比して精度を維持しつつ大幅にレイヤー数を削 減することができた。

\section{$\diamond$ 参 考 文 献 $\diamond$}

[Akiba 17] Akiba, T., Suzuki, S., and Fukuda, K.: Extremely Large Minibatch SGD: Training Resnet-50 on ImageNet in 15 Minutes, arXiv preprint arXiv:1711.04325 (2017)

[Ba 14] Ba, J. and Caruana, R.: Do Deep Nets Really Need to be Deep?, in NeurIPS, pp. 2654-2662 (2014)

[Bianco 18] Bianco, S., Cadene, R., Celona, L., and Napoletano, P.: Benchmark Analysis of Representative Deep Neural Network Architectures, IEEE Access, Vol. 6, pp. 64270-64277 (2018)

[Canziani 16] Canziani, A., Paszke, A., and Culurciello, E.: An Analysis of Deep Neural Network Models for Practical Applications, arXiv preprint arXiv: 1605.07678 (2016)

[Chen 17] Chen, G., Choi, W., Yu, X., Han, T. X., and Chandraker, M.: Learning Efficient Object Detection Models with Knowledge Distillation, in NeurIPS, pp. 742-751 (2017)

[Cheng 18] Cheng, J., Wang, P., Li, G., Hu, Q., and Lu, H.: Recent Advances in Efficient Computation of Deep Convolutional Neural Networks, Frontiers of IT \& EE, Vol. 19, No. 1, pp. 64-77 (2018)

[Fujiwara 16a] Fujiwara, Y., Ida, Y., Arai, J., Nishimura, M., and Iwamura, S.: Fast Algorithm for the Lasso based L1-Graph Construction, PVLDB, Vol. 10, No. 3, pp. 229-240 (2016)

[Fujiwara 16b] Fujiwara, Y., Ida, Y., Shiokawa, H., and Iwamura, S.: Fast Lasso Algorithm via Selective Coordinate Descent, in AAAI, pp. 1561-1567 (2016)

[Greff 16] Greff, K., Srivastava, R. K., and Schmidhuber, J.: Highway and residual networks learn unrolled iterative estimation, arXiv preprint arXiv:1612.07771 (2016)

[Han 15] Han, S., Pool, J., Tran, J., and Dally, W. J.: Learning both Weights and Connections for Efficient Neural Network, in NeurIPS, pp. 1135-1143 (2015)

[He 15] He, K., Zhang, X., Ren, S., and Sun, J.: Delving Deep into Rectifiers: Surpassing Human-Level Performance on ImageNet Classification, in ICCV, pp. 1026-1034 (2015)

[He 16a] He, K., Zhang, X., Ren, S., and Sun, J.: Deep Residual Learning for Image Recognition, in CVPR, pp. 770-778 (2016)

[He 16b] He, K., Zhang, X., Ren, S., and Sun, J.: Identity Mappings in Deep Residual Networks, in ECCV, pp. 630-645 (2016)
[He 17] He, Y., Zhang, X., and Sun, J.: Channel Pruning for Accelerating Very Deep Neural Networks, in ICCV, pp. 1398-1406 (2017)

[He 18] He, Y., Kang, G., Dong, X., Fu, Y., and Yang, Y.: Soft Filter Pruning for Accelerating Deep Convolutional Neural Networks, in IJCAI, pp. 2234-2240 (2018)

[Hinton 15] Hinton, G., Vinyals, O., and Dean, J.: Distilling the Knowledge in a Neural Network, arXiv preprint arXiv:1503.02531 (2015)

[Huang 18] Huang, Z. and Wang, N.: Data-Driven Sparse Structure Selection for Deep Neural Networks, in ECCV (2018)

[Ida 17] Ida, Y., Fujiwara, Y., and Iwamura, S.: Adaptive Learning Rate via Covariance Matrix Based Preconditioning for Deep Neural Networks, in IJCAI, pp. 1923-1929 (2017)

[Ida 19] Ida, Y., Fujiwara, Y., and Kashima, H.: Fast Sparse Group Lasso, in NeurIPS, pp. 1700-1708 (2019)

[Ioffe 15] Ioffe, S. and Szegedy, C.: Batch Normalization: Accelerating Deep Network Training by Reducing Internal Covariate Shift, in ICML, pp. 448-456 (2015)

[Kingma 14] Kingma, D. P. and Ba, J.: Adam: A Method for Stochastic Optimization, arXiv preprint arXiv:1412.6980 (2014)

[Krizhevsky 09] Krizhevsky, A. and Hinton, G.: Learning Multiple Layers of Features from Tiny Images (2009)

[Krizhevsky 12] Krizhevsky, A., Sutskever, I., and Hinton, G. E.: ImageNet Classification with Deep Convolutional Neural Networks, in NeurIPS, pp. 1097-1105 (2012)

[LeCun 98] LeCun, Y., Bottou, L., Bengio, Y., and Haffner, P.: Gradient-based Learning Applied to Document Recognition, Proceedings of the IEEE, Vol. 86, No. 11, pp. 2278-2324 (1998)

[Li 16] Li, H., Kadav, A., Durdanovic, I., Samet, H., and Graf, H. P.: Pruning Filters for Efficient Convnets, arXiv preprint arXiv:1608.08710 (2016)

[Liu 17] Liu, Z., Li, J., Shen, Z., Huang, G., Yan, S., and Zhang, C.: Learning Efficient Convolutional Networks through Network Slimming, in ICCV, pp. 2755-2763 (2017)

[Liu 19] Liu, Z., Mu, H., Zhang, X., Guo, Z., Yang, X., Cheng, K. T., and Sun, J.: MetaPruning: Meta Learning for Automatic Neural Network Channel Pruning, in ICCV, pp. 3295-3304 (2019)

[Luo 17] Luo, J., Wu, J., and Lin, W.: ThiNet: A Filter Level Pruning Method for Deep Neural Network Compression, in ICCV, pp. 5068 5076 (2017)

[Mishra 17] Mishra, A. and Marr, D.: Apprentice: Using Knowledge Distillation Techniques to Improve Low-precision Network Accuracy, arXiv preprint arXiv:1711.05852 (2017)

[Peng 19] Peng, H., Wu, J., Chen, S., and Huang, J.: Collaborative Channel Pruning for Deep Networks, in ICML, pp. 5113-5122 (2019)

[Robbins 51] Robbins, H. and Monro, S.: A Stochastic Approximation Method, Ann. Math. Stat, pp. 400-407 (1951)

[Russakovsky 15] Russakovsky, O., Deng, J., Su, H., Krause, J., Satheesh, S., Ma, S., Huang, Z., Karpathy, A., Khosla, A., Bernstein, M. S., Berg, A. C., and Li, F.: ImageNet Large Scale Visual Recognition Challenge, IJCV, Vol. 115, No. 3, pp. 211-252 (2015)

[Schuster 10] Schuster, M.: Speech Recognition for Mobile Devices at Google, in PRICAI, pp. 8-10 (2010)

[Simonyan 14] Simonyan, K. and Zisserman, A.: Very deep convolutional networks for large-scale image recognition, arXiv preprint arXiv:1409.1556 (2014)

[Szegedy 15] Szegedy, C., Liu, W., Jia, Y., Sermanet, P., Reed, S. E., Anguelov, D., Erhan, D., Vanhoucke, V., and Rabinovich, A.: Going Deeper with Convolutions, in CVPR, pp. 1-9 (2015)

[Veit 16] Veit, A., Wilber, M. J., and Belongie, S. J.: Residual Networks Behave Like Ensembles of Relatively Shallow Networks, in NeurIPS, pp. 550-558 (2016)

[Veit 18] Veit, A. and Belongie, S. J.: Convolutional Networks with Adaptive Computation Graphs, in ECCV, pp. 3-18 (2018)

[Wu 16] Wu, J., Leng, C., Wang, Y., Hu, Q., and Cheng, J.: Quantized Convolutional Neural Networks for Mobile Devices, in CVPR, pp. 4820-4828 (2016)

[Wu 18 Wu, Z., Nagarajan, T., Kumar, A., Rennie, S., Davis, L. S., Grauman, K., and Feris, R. S.: BlockDrop: Dynamic Inference Paths in Residual Networks, in CVPR, pp. 8817-8826 (2018) 


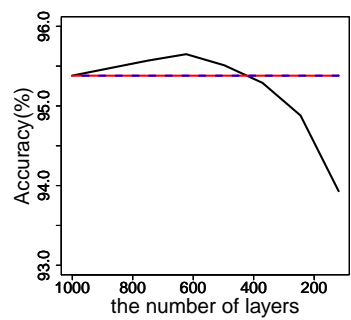

(a) CIFAR10

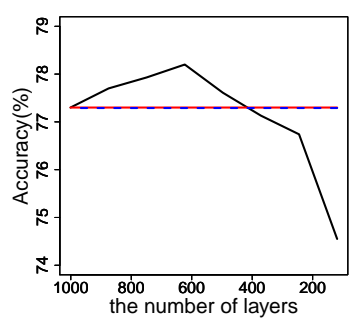

(b) CIFAR100
図 A.1 1001 層の ResNet における精度とレイヤー数. 提案手法は 1001 層の ResNet の精度を 497 層まで維持できた.

表 A.1 1001 層の ResNet と精度劣化していない 497 層の ResNet の推論 (順伝播) の計算時間及びモデルサイズ.

\begin{tabular}{cccc}
\hline \multirow{2}{*}{ データセット } & 手法 & $\begin{array}{c}\text { 順伝播 } \\
(\mathrm{sec})\end{array}$ & $\begin{array}{c}\text { モデルサイズ } \\
(\mathrm{MB})\end{array}$ \\
\hline \multirow{2}{*}{ Cifar-10 } & ResNet & 0.239 & 85.6 \\
\cline { 2 - 4 } & 提案 & $\mathbf{0 . 1 3 7}$ & $\mathbf{4 2 . 6}$ \\
\hline \multirow{2}{*}{ Cifar-100 } & ResNet & 0.287 & 85.9 \\
\cline { 2 - 4 } & 提案 & $\mathbf{0 . 1 8 1}$ & $\mathbf{4 2 . 8}$ \\
\hline
\end{tabular}

[Xiao 17] Xiao, X., Jin, L., Yang, Y., Yang, W., Sun, J., and Chang, T.: Building Fast and Compact Convolutional Neural Networks for Offline Handwritten Chinese Character Recognition, Pattern Recognition, Vol. 72, pp. 72-81 (2017)

[Yang 18] Yang, T., Howard, A. G., Chen, B., Zhang, X., Go, A., Sandler, M., Sze, V., and Adam, H.: NetAdapt: Platform-Aware Neural Network Adaptation for Mobile Applications, in ECCV, pp. 289-304 (2018)

[Yu 18] Yu, X., Yu, Z., and Ramalingam, S.: Learning Strict Identity Mappings in Deep Residual Networks, in CVPR, pp. 4432-4440 (2018)

〔担当委員：内田 祐介]

2019 年 10 月 8 日 受理

$$
\diamond \text { 付 録 } \diamond
$$

本付録においては主に本文の実験を補う実験結果を記載する.

\section{A. ResNet-1001}

本文の CIFAR10/100 を用いた実験では 56 層の ResNet を用いて いるが，[He 16b] によると 1001 層の ResNet を用いることでさら に高い精度を達成できる．本実験ではこの 1001 層の ResNetに対 し，どこまで精度を維持しながらレイヤーを削除できるかを確認し た. 提案手法における一度に削除する Residual Unit の数 $k$ の值は, $k=42$ とした。 その他の実験設定は $[\mathrm{He} 16 \mathrm{~b}]$ に従った.

図 A.1 はレイヤー数は 1001 層から 119 層までのレイヤー数と精 度の関係を示す. 赤い点線は提案手法の 1001 層の ResNet の精度 である．青い破線は $[\mathrm{He} 16 \mathrm{~b}]$ で報告されている精度である．提案 手法は精度劣化なしで CIFAR10/100 共に 497 層までレイヤーを削 減することができた。これは 1001 層の $49.65 \%$ であり，半分以上 のレイヤーを削除できたことになる.

表 A.1 は 1001 層 ResNet と, 上記の精度劣化を起こしていない 497 層の ResNet の推論時間とモデルサイズを比較した結果である. 提案手法により CIFAR10/100 でそれぞれ 48.68\%，47.57\%の推論時 間を削減できた。また，モデルサイズに関してはそれぞれ $50.30 \%$ ， 50.26\%削減できた。

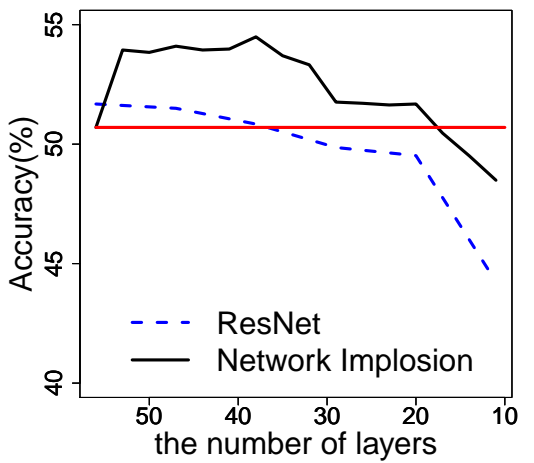

図 A.2 Tiny-ImageNet における精度とレイヤー数.

\section{B. Tiny-ImageNet}

本実験では参考值として本論文では用いられていないデータセット である Tiny-ImageNetのレイヤー削除の実験を行った. Tiny-ImageNet は ImageNet のデータセットから画像データをサンプリングし，そ の画像スケールを変更したデータセットである ${ }^{* 2}$. 本論文では 10 , 100，1000 クラスの画像分類の結果を掲載したが，Tiny-ImageNet は 200 クラスの画像分類問題となる. 画像サイズは $64 \times 64 \times 3$ と なり，それぞれのクラスには 500 の画像が含まれる．その他の実験 設定は本論文の実験設定と同様である.

図 A.2 にレイヤー削除の結果を示す. 青い破線はベースラインと なる ResNet を，黒い線は提案手法を，赤い直線は提案手法の初期 の精度を表す. 提案手法は 56 層の ResNet 20 層まで精度劣化な しに圧縮できており, タスク・モデル・データセットによっては大 幅にレイヤーを削除できることを示している.

\section{C. 追加実験の結論}

本論文の実験では画像認識分野での標準的なデータセットとモデル での結果を見せた. 追加実験では 1001 層のモデルや Tiny-ImageNet のデータセットで実験を行い, これらの設定ではレイヤー数を精度 劣化なしで 50 \%以上削減できることを示した。したがって，実際 のサービスなどにおいても元のモデルやデータセットによっては半 数以上のレイヤーを削除することも期待できると考えられる.

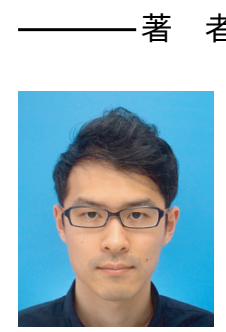

者 紹 介

\section{井田 安俊(正会員)}

2014 年早稲田大学大学院先進理工学研究科電気・情報生 命専攻修士課程修了. 同年, 日本電信電話株式会社入社. 現在, 日本電信電話株式会社 NTT ソフトウェアイノベー ションセンタ研究員及び京都大学大学院情報学研究科知能 情報学専攻博士課程に在学中. 機械学習, データマイニン グの研究開発に従事.

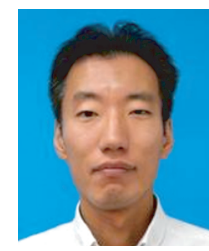

\section{藤原 靖宏}

2003 年早稲田大学大学院理工学研究科雷気工学専攻修士 課程修了. 同年, 日本電信電話株式会社入社. 2011 年東 京大学大学院情報理工学系研究科電子情報学専攻博士課程 修了. 2014 年ニューヨーク大学客員研究員。現在，日本電 信電話株式会社 NTT コミュニケーション科学基礎研究所 主任研究員. 博士 (情報理工学) . データマイニング, 人 工知能などの研究開発に従事. 情報処理学会 2015 年度長 尾真記念特別賞などを受賞. 